\title{
INDIVIDUALIZED TREATMENT OF INFANTILE HAEMANGIOMA: A CASE REPORT
}

\author{
Anca-Maria Raicu ${ }^{1}$, Ionuț Fernando Secheli ${ }^{2}$, Dana Galieta Mincă ${ }^{1}$
}

\begin{abstract}
The treatment of infantile hemangiomas has been greatly modified in the last 15 years, starting from the passive attitude, from "wait and see", to complex surgical procedures. Currently, the vast majority of infantile hemangiomas are treated with Propranolol, however there are cases where monotherapy is not sufficient, requiring a combination of existing treatment methods. The complexity of the therapy is determined by the complexity of the infantile hemangioma: an extended or exposed area, local complications as ulceration etc. In the present case, a clinical situation is described in which we added to the drug treatment (with oral Propranolol) the local treatment (with Timololum gel) and the surgical procedure of partial excision of hemangioma. Our goal is to highlight the importance of knowing the treatment methods and their possibilities of combination, for a better aesthetic and functional result.
\end{abstract}

Keywords: infantile hemangioma, Propranolol, infantile hemangioma treatment, complications of infantile hemangioma.

\section{Introduction}

Infantile hemangioma (HI) is the most common benign tumor of the child, with an average incidence of $4 \%$ to $5 \%$ (13 ) and a maximum incidence of $10 \%-12 \%$, found in nonHispanic Caucasian infants. At the same time, infantile hemangioma is considered not only the most common benign tumor of the child, but also the most common vascular tumor, which occurs by rapid division of endothelial cells, its growth being attributed to hyperplasia of these cells. The pathogenesis of infantile hemangiomas is complex and little understood and known. Risk factors include prematurity and placental abnormalities (4).

Infantile hemangiomas most commonly occur on the skin but can also affect the viscera (the liver is most often involved). Facial hemangiomas can be impressive in appearance, disfiguring, sometimes affecting visual function, with eating disorders, and those in the airways can be lifethreatening, especially in the proliferative phase (5-6).

The treatment of childhood hemangiomas includes a wide range of approaches, from conservative monitoring "wait and see", to emergency surgery for severe morbidity and complications. Early treatment can reduce complications. However, there are so many therapeutic protocols ( $\beta$ systemic or topical blockers, corticosteroids, laser therapy, etc.) (7-8) that it is almost impossible for clinicians to choose the best therapeutic method.

Given the high heterogeneity of hemangiomas, the decision on who needs treatment as well as when to start treatment requires a detailed knowledge of the natural history and clinical indicators of high risk.

\section{Aim}

Our goal was to highlight the importance of knowing all the methods of treatment of infantile hemangiomas and adapting the therapeutic approach according to the complexity of the case, for an aesthetic and functional result as good as possible.

\section{Material and method}

We present the case of a little girl, who addressed the paediatric surgery service of the Emergency Clinical Hospital for Children „M. S. Curie”, at the age of 3 months, for a vascular abnormality that included two lower thirds of the arm and two upper thirds of the left forearm, appeared at 3 weeks postnatal (Fig. 1), with rapid and unfavorable evolution, towards ulceration on the arm (Fig. 2).

Following the clinical examination, corroborated with the anamnestic data (moment of appearance, evolution, etc.), the diagnosis of infantile hemangioma is made, and it is decided to hospitalize for specialized investigations, in order to establish the treatment as soon as possible.

Since 2008, the treatment of infantile hemangiomas has been revolutionized by the introduction of Propranolol, a beta blocker, with superior results and much lower side effects compared to previously used drugs (9-17), a method quickly approved and implemented in our country.

Although there is currently no generally accepted infantile hemangioma management protocol, in our team, Propranolol treatment is not instituted until a detailed paediatric, cardiology, surgical and imaging examination, which includes a complete biological assessment, an electrocardiogram, a heart ultrasound, a soft tissue ultrasound, a trans fontanel ultrasound (for hemangiomas in the cephalic extremity), an abdominal ultrasound (for thoraco-abdominal hemangiomas) and for selected cases of an MRI. Following the investigations performed and clinical data, no pathological changes were found, which would contraindicate the start of oral treatment with Propranolol.

1 "Carol Davila" University of Medicine and Pharmacy, Bucharest, Romania

2 "M.S. Curie" Clinical Emergency Hospital for Children, Bucharest, Romania

Email: anca.raicu@drd.umfcd.ro,tacclo@hotmail.com, dana.minca@umfcd.ro 


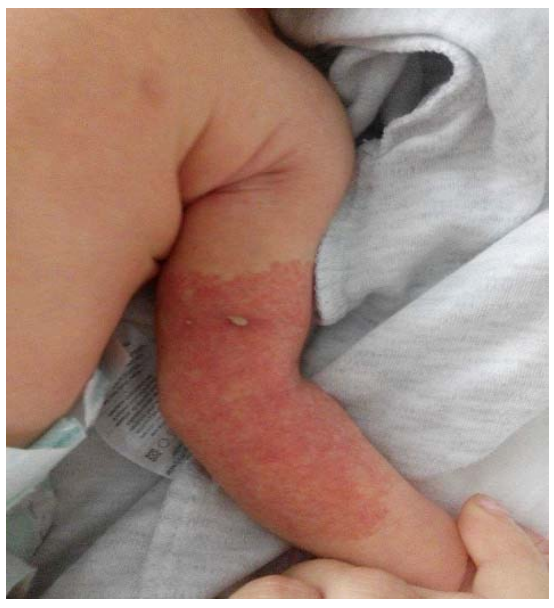

Fig. 1. Aspect of the hemangioma at 3 weeks of age

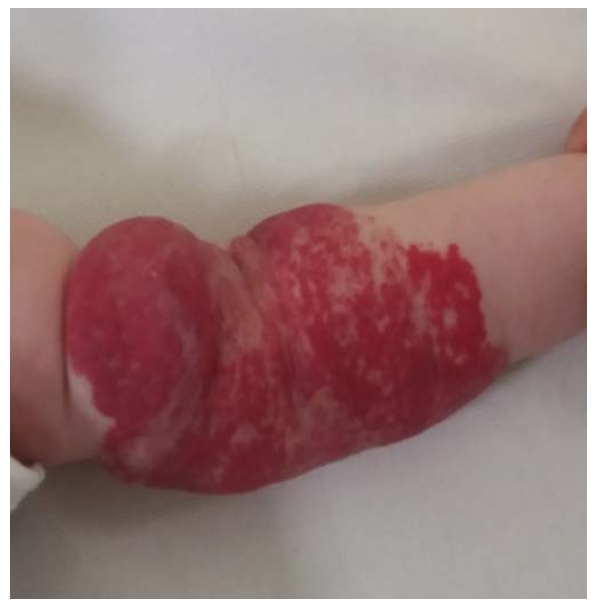

Fig. 3. Aspect of the haemangioma after 3 months of treatment with Propranolol

\section{Discussions}

Infantile hemangiomas remain the most common vascular tumors of the child, which appear in the first month of life and which often involve spontaneously, gradually, after the age of 1 year in their vast majority. Their clinical presentation varies from minimal skin lesions to impaired vital functions (example: hemangiomas that cause respiratory or visual disturbances) or disfiguring lesions. The most common complication of infantile hemangiomas is ulceration (20-23), who's healing by re-epithelialization is most often done with unsightly and disabling scars.

Infantile hemangioma is a great clinical challenge, from diagnosis to treatment (Should we treat or should we wait and

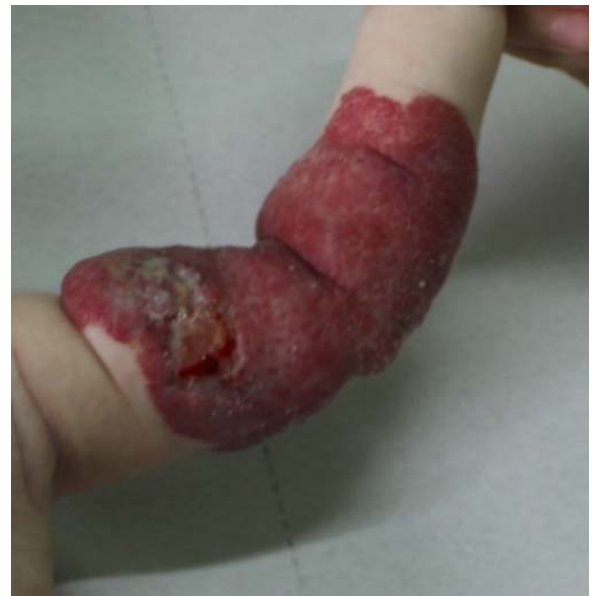

Fig. 2. Aspect of the haemangioma at 3 months of age

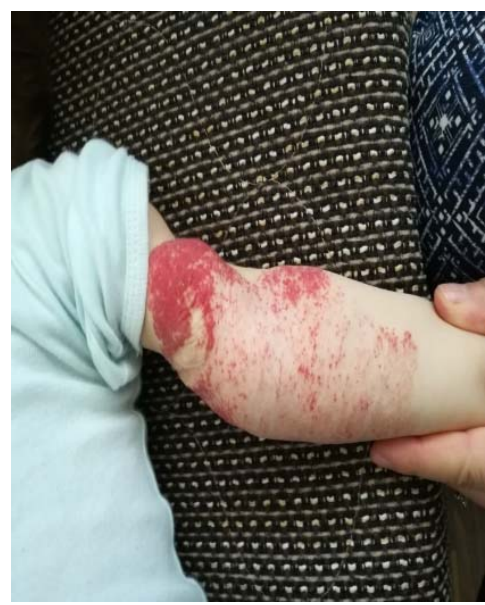

Fig. 4. Aspect of the haemangioma after 13 months of treatment with Propranolol

see? If we decide to treat the hemangioma, what type of treatment should we recommend? How long?).

Although the introduction of Propranolol in the treatment of infantile hemangiomas, which is currently the first line of treatment, no consensus has been reached on the optimal time to initiate treatment or its duration. There are authors who specify that the duration would be 6 to a maximum of 12 months for high-risk hemangiomas (18), but as we present, in selected cases this period can be extended until the complete remission of the lesions. Regarding the time of initiation, it is recommended to be done at the age of 5 weeks of life, but this term can be advanced in situations where the evolution of hemangioma is rapidly unfavorable and if the bio-humoral status of the patient allows us. In this 
case, the initiation of treatment was made from the presentation, at 3 months of age (approximately 12 weeks), when he addressed our service (presentation determined by the appearance of ulceration and less by the increase in size of the hemangioma). An early treatment could have limited the spread of hemangioma, prevented the onset of ulceration, decreased the duration of subsequent treatment, perhaps even the need for surgery. It would also have reduced treatment costs, both for the health care provider and for the family. But most importantly, the child's suffering would have decreased.

\section{Conclusions}

Establishing the correct diagnosis, as early as possible, by the multidisciplinary team is the first step in approaching

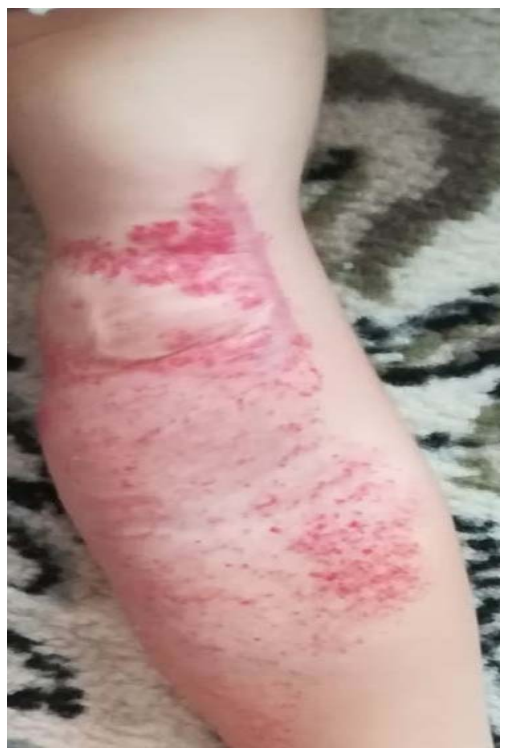

Fig. 5. Aspect of the haemangioma after 1 year and 6 months of treatment with Propranolol and 3 months after surgery these patients. Choosing the appropriate treatment for the case, under close monitoring, can prevent complications, and their correction as close as possible to normal, in terms of appearance and function of the affected organ.

Knowing all the treatment methods, the possibilities of combining them, teamwork, as well as adapting the approach according to the particularities of the case is the key to success in these complex situations, with good results.

We also consider that it is necessary to develop a standardized protocol for the management of cases of infantile hemangiomas, which should come to the aid of the clinician whose object of activity is this pathology.

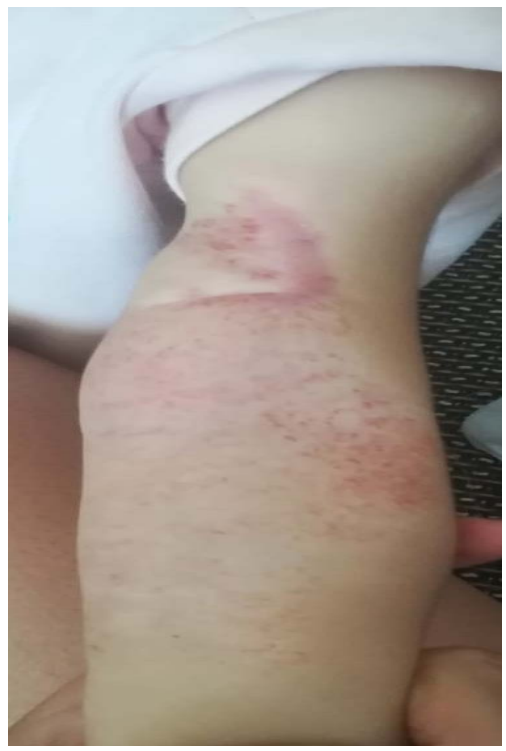

Fig. 6. Hemangioma at the age of 2 years, after 20 months of oral Propranolol, 4 months of Timololum gel, and one surgical intervention

\section{References}

1. Munden A, Butschek R, Tom WL, et al. Prospective study of infantile hemangiomas: incidence, clinical characteristics and association with placental anomalies. Br J Dermatol 2014;170:907-13

2. Dickison P, Christou E, Wargon O. A prospective study of infantile hemangiomas with a focus on incidence and risk factors. Pediatr Dermatol 2011; 28:663-9

3. Frieden IJ, Haggstrom AN, Drolet BA, et al. Infantile hemangiomas: current knowledge, future directions. Pediatr Dermatol 2005; 22:383-406
4. Haggstrom AN, Drolet BA, Baselga E, et al. Prospective study of infantile hemangiomas: demographic, prenatal, and perinatal characteristics. J Pediatr 2007; 150:291-4

5. Krowchuk DP, Frieden IJ, Mancini AJ, et al. Clinical practice guideline for the management of infantile hemangiomas. Pediatrics 2019;143:e20183475.

6. Jacobs AH. Strawberry hemangiomas: The natural history of the untreated lesion. Calif Med. 1957; 86:810. 
7. Léauté-Labrèze C, Harper JI, Hoeger PH. Infantile hemangioma. Lancet 2017; 390:85-94.

8. Hoeger PH, Harper JI, Baselga E, et al. Treatment of infantile hemangiomas: recommendations of a european expert group. Eur J Pediatr 2015;174: 855-65.

9. Léauté-Labrèze $\mathrm{C}$, Dumas de la Roque E, Hubiche T, Boralevi F, Thambo JB, Taïeb A. Propranolol for severe hemangiomas of infancy. $\mathrm{N}$ Engl $\mathrm{J}$ Med. 2008;358(24):2649-2651

10. Sans V, de la Roque ED, Berge J, et al. Propranolol for severe infantile hemangiomas: follow-up report. Pediatrics. 2009;124(3).

11. Bertrand J, McCuaig C, Dubois J, Hatami A, Ondrejchak S, Powell J. Propranolol versus prednisone in the treatment of infantile hemangiomas: a retrospective comparative study. Pediatr Dermatol. 2011;28(6):649654

12. Price CJ, Lattouf C, Baum B, et al. Propranolol vs corticosteroids for infantile hemangiomas: a multicenter retrospective analysis. Arch Dermatol. 2011;147(12):1371-1376

13. Hogeling $\mathrm{M}$, Adams $\mathrm{S}$, Wargon O. A randomized controlled trial of propranolol for infantile hemangiomas. Pediatrics. 2011;128(2).

14. Léauté-Labrèze C, Dumas de la Roque E, Nacka F, et al. Double-blind randomized pilot trial evaluating the efficacy of oral propranolol on infantile hemangiomas in infants $<4$ months of age. $\mathrm{Br} \mathrm{J}$ Dermatol. 2013;169(1):181-183

15. Léauté-Labrèze $C$, Hoeger $P$, Mazereeuw-Hautier J, et al. A randomized, controlled trial of oral propranolol in infantile hemangioma. N Engl J Med. 2015;372(8):735746

16. Chang L, Gu Y, Yu Z, et al. When to stop propranolol for infantile hemangioma. Sci Rep. 2017;7:43292

17. Tan ST, Itinteang T, Leadbitter P. Low-dose propranolol for infantile hemangioma. J Plast Reconstr Aesthet Surg. 2011;64(3):292-299

18. Baselga E, Dembowska-Baginska B, Przewratil P, González-Enseñat MA, et al. Efficacy of Propranolol Between 6 and 12 Months of Age in High-Risk Infantile Hemangioma. Pediatrics. 2018 Sep;142(3):e20173866. doi: 10.1542/peds.2017-3866. Epub 2018 Aug 6.

19. Esterly NB. Cutaneous hemangiomas, vascular stains and malformations, and associated syndromes. Curr Probl Dermatol. 1995; VII (3):65-108

20. Haggstrom AN, Drolet BA, Baselga E, et al. Prospective study of infantile hemangiomas: clinical characteristics predicting complications and treatment. Pediatrics. 2006; 118(3):882-887

21. Mulliken JB. Diagnosis and natural history of hemangiomas. In: Mulliken JB, Young MA, eds. Vascular Birthmarks: Hemangiomas and Malformations. Philadelphia: Saunders; 1988: 41-62.

22. Kim HJ, Colombo M, Frieden IJ. Ulcerated hemangiomas: clinical characteristics and response to therapy. J Am Acad Dermatol. 2001;44(6):962-972

23. Gampper TJ, Morgan RF. Vascular anomalies: hemangiomas. Plast Reconstr Surg. 2002;110(2):572588

\section{Correspondence to:}

Anca Raicu

"Carol Davila" University of Medicine and Pharmacy37

Dionisie Lupu Street, 2nd Sector, Bucharest

Phone: 0721681280

Email: anca.raicu@drd.umfcd.ro 